\title{
Mengukur Performa Enterprise Architecture Framework Menggunakan Fuzzy Tsukamoto
}

\author{
Fakri Fandy Nur Azizi, Wayan Firdausi Mahmudy
}

\begin{abstract}
Abstact - Enterprise Architecture (EA) is a description of the mission of the stakeholders that describes the development plan of a system or set of systems to achieve an organization's mission through optimal performance of business processes within an IT environment efficiently. To enforce EA within an organization requires a fundamental framework and a set of support tools that are used to develop an EA. EA performance measurement framework, as necessary, to determine the EA framework that is applicable to the current conditions. So it takes a decision support to help select EA framework is based on the assessment criteria of the artifact, governance, strategy, consistency, requirements, guidelines, and continual. In this paper discussed making Decission support system for measuring the performance of EA framework using Tsukamoto Fuzzy Inference System. The parameters used to limit the fuzzy membership functions based on data obtained from experts that the artifact, governance, strategy, consistency, requirements, guidelines, and continual. The accuracy of the system is calculated based on the comparison of the output of the system with the results of the expert assessment. Based on the test results indicate that the system produces an accuracy of $67 \%$.
\end{abstract}

Keyword : Performa, Enterprise Architecture, EA Framework, Fuzzy Tsukamoto

Abstrak--Enterprise Architecture (EA) adalah deskripsi dari misi stakeholder yang menggambarkan rencana pengembangan sebuah sistem atau sekumpulan sistem untuk mencapai sebuah misi organisasi melalui performansi optimal dari proses bisnis dalam sebuah lingkungan TI yang efisien. Untuk bisa menerapkan EA dalam sebuah organisasi, dibutuhkan kerangka kerja yang bersifat fundamental dan satu set alat pendukung yang digunakan untuk mengembangkan suatu EA. Pengukuran performa EA framework dirasa perlu, untuk mengetahui EA framework yang applicable pada kondisi saat ini. Sehingga dibutuhkan sebuah decision support untuk membantu memilih EA framework berdasarkan kriteria penilaian dari sisi artifact, governance, strategy,

This work was supported in part by Computer Science Department of Brawijaya University, Malang.

Fakri Fandy Nur Azizi was with Computer Science Department of Brawijaya University, Malang, Indonesia (corresponding author email fakrifandy@gmail.com)

Wayan F Mahmudy was with Computer Science Department of Brawijaya University, Malang, Indonesia (corresponding author email wayanfm@ub.ac.id) consistency, requirement, guidelines, dan continual. Pada makalah ini dibahas pembuatan decission support system untuk mengukur performa EA framework menggunakan Sistem Inferensi Fuzzy Tsukamoto. Parameter yang digunakan untuk batasan fungsi keanggotaan fuzzy berdasarkan data yang diperoleh dari pakar yaitu artifact, governance, strategy, consistency, requirement, guidelines, dan continual. Akurasi sistem dihitung berdasarkan hasil perbandingan dari keluaran sistem dengan hasil penilaian pakar. Berdasarkan hasil pengujian menunjukkan bahwa sistem yang dibangun menghasilkan akurasi $67 \%$.

Kata Kunci : Performa, Enterprise Architecture, EA Framework, Fuzzy Tsukamoto

\section{PENDAHULUAN}

\subsection{Latar Belakang}

Dengembangan teknologi informasi pada sebuah Porganisasi skala besar guna membantu pengembangan bisnis sudah menjadi kebutuhan yang tidak dapat dihindari.

Menurut Yunis, Surendro, Panjaitan sering kali ditemukan bahwa pengembangan yang dilakukan belum sesuai dengan kebutuhan yang sebenarnya dari perusahaan [1]. Dalam pengembangan sebuah sistem yang sesuai dengan kebutuhan bisnis memang membutuhkan perencanaan dan perancangan sistem yang tepat [2].

Enterprise Architecture (EA) merupakan suatu mekanisme untuk menggambarkan perencanaan sistem secara logis, menyeluruh dan holistik. Perencanaan tersebut diterapkan pada sebuah organisasi dengan melibatkan seluruh komponen sistem secara simultan [3].

Agar penerapan Enterprise Architecture dalam pemodelan sekumpulan sistem dapat maksimal, menurut Magoulas, Hadzic dibutuhkan sebuah kerangka kerja (framework) yang dapat memodelkan berbagai fase Enterprise Architecture secara rinci [4]. Kerangka kerja ini diharapkan mampu mengelola sistem yang kompleks dan menyelaraskan antara teknologi yang dikembangkan dan bisnis dari perusahaan.

Ada beberapa framework yang bisa digunakan untuk memodelkan setiap fase EA, seperti Enterprise Architecture Planning (EAP), Federal Enterprise Architecture Framework (FEAF), Department of Defense Architecture Framework (DODAF), Gartner dan The Open Grup Architecture Framework (TOGAF) 
[5]. Oleh karena itu, dibutuhkan metode pengambilan keputusan untuk menentukan framework yang memiliki fungsi dan pendekatan yang cocok dengan kebutuhan perusahaan.

Terdapat penelitian sebelumnya yang menggunakan metode AHP dan Fuzzy AHP dalam pemilihan EA framework untuk mengetahui kandidat arsitektur terbaik yang sesuai dengan atribut EA yang diberikan [6]. Namun metode AHP tidak lagi efektif jika digunakan pada permasalah yang memiliki alternatif dan jumlah kriteria yang banyak [5]. AHP juga merupakan metode matematis yang bergantung pada inputan utama yang dipengaruhi oleh subjektifitas ahli dan tanpa ada pengujian secara statistik, sehingga muncul masalah terkait sulitnya menentukan bobot dari masing-masing kriteria. Untuk menangani kekurangan AHP tersebut diperlukan metode yang lebih memperhatikan kriteria-kriteria yang bersifat subjektif.

Dalam makalah ini penulis mengusulkan metode Fuzzy Tsukamoto untuk mengukur performa Enterprise Architecture Framework untuk pemodelan sekumpulan sistem secara holistik. Ada tujuh parameter yang menjadi masukan bagi sistem inferensi fuzzy Tsukamoto pada penelitian ini, yaitu artifact, governance, strategy, consistency, requirement, guidelines, dan continual. Proses penelitian menggunakan fuzzy Tsukamoto akan dilakukan dengan memberikan pembobotan pada setiap parameter yang terdapat pada penilaian uji performa EA framework. Kemudian nilai keanggotaan dari tiap - tiap parameter dihitung sehingga menghasilkan nilai dan predikat performa dari setiap EA framework berdasarkan kategori dan nilai untuk seluruh kriteria. Nilai dan predikat inilah yang menjadi nilai performa EA framework.

\section{LANDASAN TEORI}

\subsection{Enterprise Architecture}

Ada beberapa pendapat mengenai pengertian Enterprise Architecture (EA). Diantara pengertian EA adalah sebagai berikut :

1. Enterprise Aechitecture merupakan deskripsi dari tujuan stakeholder yang didalamnya terdapat informasi, fungsionalitas, lokasi organisasi dan parameter kinerja. EA digunakan untuk menggambarkan rencana untuk pengembangan sebuah sistem atau sekumpulan sistem [8].

2. Menurut Ducet dkk, EA secara berkelanjutan dapat mempengaruhi manajemen organisasi dan sektor teknologi pada sebuah organisasi untuk mengembangkan sebuah blueprint sistem informasi [9] dari berbagai disiplin baik secara teori maupun praktis.

\subsection{Enterprise Architecture Framework}

Enterprise Architecture Framework (EAF) adalah sebuah kerangka kerja untuk membuat rancangan yang bersifat fundamental dari sebuah organisasi yang menggambarkan visi, misi dan proses bisnis dari organisasi tersebut. Dimana fungsi enterprise architecture digunakan untuk menggambarkan rencana pengembangan sebuah sistem atau sekumpulan sistem [10].

Istilah Enterprise Architecture Framework dipopulerkan oleh John A. Zachman pada tahun (1980) yang menyebutkan bahwa Enterprise Architecture adalah deskripsi dari misi yang diemban stakeholder yang didalamnya termasuk informasi, fungsi, lokasi organisasi dan parameter kerja dalam organisasi [3].

\subsection{Logika Fuzzy}

Logika fuzzy merupakan inti dari soft computing untuk memetakan suatu ruang input ke dalam suatu ruang output dan memiliki nilai kontinyu. Nilai 0 sampai dengan 1 adalah derajat keanggotaan yang berlaku pada logika fuzzy. Dimana nilai kebenaran dari suatu pernyataan bisa berarti sebagian benar dan sebagian salah dalam tempo yang bersamaan [10].

\section{Metodologi Penelitian}

Sebelum menuju pada tahap perhitungan menggunakan sistem inferensi fuzzy, data rentang nilai kriteria yang akan dijadikan data uji performa EA framework harus ditentukan terlebih dahulu. Berdasarkan data parameter pengujian performa EA framework [5] yang didapat, maka dibuatlah rentang nilai kriteria dari 7 kriteria pengujian, yaitu K1 adalah Artifact, K2 adalah Governance, K3 adalah Strategy, K4 adalah Consistency, K5 adalah Requirement, K6 adalah Guidelines, dan K7 adalah Continual. Berdasarkan data yang diperoleh, maka berikut penjelasan lebih detail mengenai rentang nilai pengukuran performa EA framework yang ditampilkan pada Tabel 1 .

Tabel 1. Rentang Nilai Pengukuran Performa EAF

\begin{tabular}{cc}
\hline Kriteria & Range Nilai \\
\hline K1 (Artifact) & $0-100$ \\
K2 (Governance) & $0-100$ \\
K3 (Strategy) & $0-100$ \\
K4 (Consistency) & $0-100$ \\
K5 (Requirement) & $0-100$ \\
K6 (Guidelines) & $0-100$ \\
K7 (Continual) & $0-100$ \\
\hline
\end{tabular}

Setelah data rentang nilai didefinisikan, berikut ini disajikan salah satu data EA framework yaitu Zachman Framework yang akan dijadikan nilai input pada setiap kriteria.

Tabel 2. Data Zachman Framework

\begin{tabular}{cc}
\hline Kriteria & Nilai Input \\
\hline K1 (Artifact) & 38 \\
K2 (Governance) & 78 \\
K3 (Strategy) & 36.5 \\
K4 (Consistency) & 55 \\
K5 (Requirement) & 64.5 \\
K6 (Guidelines) & 62 \\
K7 (Continual) & 60 \\
\hline
\end{tabular}

\subsection{Himpunan Fuzzy}

Secara umum himpunan fuzzy memiliki 2 atribut, yaitu numerik dan linguistik. Atribut numerik 
merupakan sebuah nilai yang merepresentasikan ukuran dari sebuah variabel. Sedangkan atribut linguistik adalah penggunaan nama dari suatu kesatuan tertentu yang menggunakan bahasa dan mewakili suatu keadaan tertentu dalam suatu variabel [11].

Pada penelitian ini, digunakan himpunan fuzzy dengan 3 nilai linguistik, yaitu Low, Medium dan High Consideration. Nilai linguistik disatukan dengan fuzzy set, dimana dari setiap nilai memiliki fungsi keanggotaan yang telah didefinisikan [12].

Tabel 3. Himpunan Fuzzy

\begin{tabular}{|c|c|}
\hline Kriteria & Nilai Linguistik \\
\hline K1 (Artifact) & $\begin{array}{l}\text { Low Consideration } \\
\text { Medium Consideration } \\
\text { High Consideration }\end{array}$ \\
\hline K2 (Governance) & $\begin{array}{l}\text { High Level Description } \\
\text { Little Description } \\
\text { Clear Description }\end{array}$ \\
\hline K3 (Strategy) & $\begin{array}{l}\text { High Level Description } \\
\text { Little Description } \\
\text { Clear Description }\end{array}$ \\
\hline K4 (Consistency) & $\begin{array}{l}\text { High Level Description } \\
\text { Little Description } \\
\text { Clear Description }\end{array}$ \\
\hline K5 (Requirement) & $\begin{array}{l}\text { High Level Description } \\
\text { Little Description } \\
\text { Clear Description }\end{array}$ \\
\hline K6 (Guidelines) & $\begin{array}{l}\text { High Level Description } \\
\text { Little Description } \\
\text { Clear Description }\end{array}$ \\
\hline K7 (Continual) & $\begin{array}{l}\text { High Level Description } \\
\text { Little Description } \\
\text { Clear Description }\end{array}$ \\
\hline
\end{tabular}

\subsection{Fuzzifikasi}

Proses fuzzifikasi merupakan proses menghitung nilai masukan dari bentuk crisp menjadi fuzzy set dengan suatu fungsi keanggotannya masing-masing. Perhitungan dalam proses fuzzifikasi berdasarkan batasbatas fungsi keanggotaan [13]. Berikut adalah fungsi keanggotaan himpunan fuzzy dengan menggunakan 3 kriteria input.

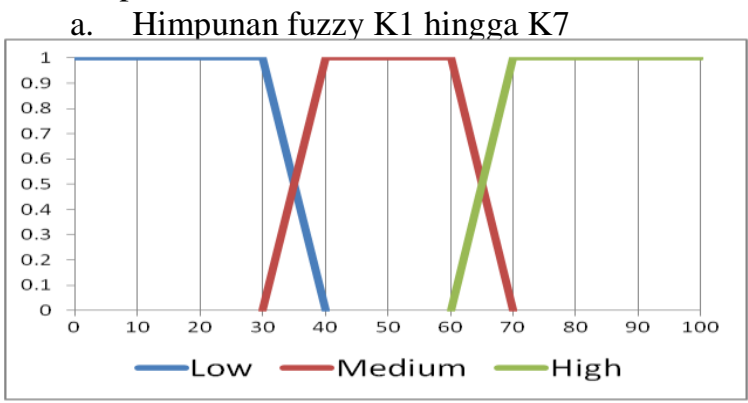

Gambar 1. Himpunan fuzzy K1 hingga K7
Fungsi derajat keanggotaan dari variabel K1 hingga K7 yang ditunjukkan pada Gambar 1, didefinisikan sebagai berikut :

Derajak keanggotaan Low Consideration

$\mu_{\text {High level }}[X]=\left\{\begin{array}{c}1 ; x \leq 30 \\ \frac{(40-x)}{(40-30)} ; 30<x>40 \\ 0 ; x \geq 40\end{array}\right.$

Derajak keanggotaan Medium Consideration

$\mu_{\text {Little }}[X]=\left\{\begin{array}{c}1 ; 40<x>70 \\ \frac{40-x}{40-30} ; 30<x>40 \\ \frac{80-x}{80-70} ; 70<x>80 \\ 0 ; 30<x>80\end{array}\right.$

Derajak keanggotaan High Consideration

$\mu_{\text {Clear }}[X]=\left\{\begin{array}{c}1 ; x>80 \\ \frac{80-x}{80-70} ; 70<x>80 \\ 0 ; x<70\end{array}\right.$

b. Himpunan hasil fuzzy

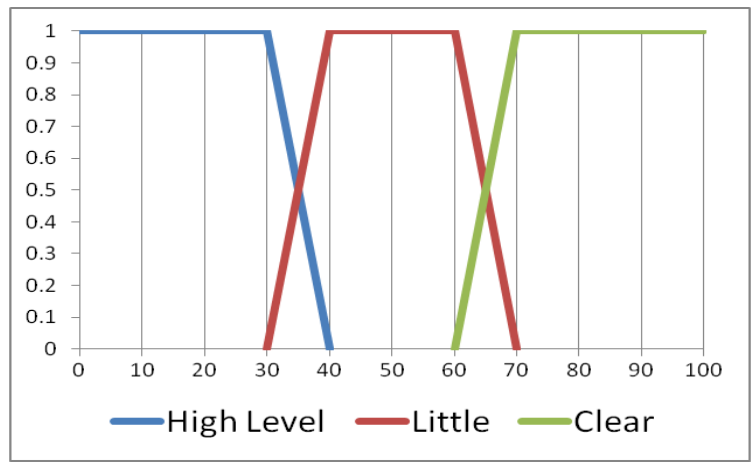

Gambar 2. Himpunan hasil fuzzy

Fungsi derajat keanggotaan dari hasil fuzzy yang ditunjukkan pada Gambar 2, didefinisikan sebagai berikut :

Derajak keanggotaan High Level Description

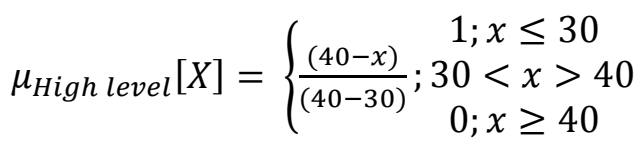

Derajak keanggotaan Little Description

$\mu_{\text {Little }}[X]=\left\{\begin{array}{c}1 ; 40<x>70 \\ \frac{40-x}{40-30} ; 30<x>40 \\ \frac{80-x}{80-70} ; 70<x>80 \\ 0 ; 30<x>80\end{array}\right.$ 
Derajak keanggotaan Clear Description

$\mu_{\text {Clear }}[X]=\left\{\begin{aligned} 1 ; x & >80 \\ \frac{80-x}{80-70} ; 70<x & >80 \\ 0 ; x & <70\end{aligned}\right.$

\subsection{Sistem Inferensi Fuzzy}

Dalam sistem inferensi fuzzy terdapat masukan fuzzy yang berupa nilai crisp. Sistem inferensi pada metode fuzzy Tsukamoto akan membentuk sebuah aturan dasar dalam bentuk "IF-THEN".

Langkah pertama pada perhitungan metode fuzzy Tsukamoto yaitu dengan membuat aturan atau rule. Langkah berikutnya, melangkah pada proses menghitung derajat keanggotaan sesuai dengan rule yang yang sudah ditentukan. Setelah nilai derajat keanggotaan dari setiap aturan diketahui, maka nilai alpha dapat diketahui dengan cara mengoperasikan himpunan fuzzy [12]. Rule base sistem inferensi fuzzy Tsukamoto untuk pengujian performa EA framework disajikan pada Tabel 4.

Tabel 4. Contoh Rule yang Digunakan Pada Penelitian

\begin{tabular}{lc}
\hline No & Rule \\
\hline
\end{tabular}

IF Artifact $=$ High AND Governance $=$ High AND Strategy = High AND Consistency = High

1 AND Requirement $=$ High AND Guidelines $=$ High AND Continual $=$ High THEN Framework Status $=$ Clear Description

IF Artifact $=$ Medium AND Governance $=$ Medium AND Strategy = High AND

2 Consistency $=$ Heigh AND Requirement $=$ High AND Guidelines $=$ High AND Continual $=$ High THEN Framework Status $=$ Clear Description

IF Artifact $=$ Medium AND Governance $=$ Medium AND Strategy = Medium AND

3 Consistency $=$ Medium AND Requirement $=$ Medium AND Guidelines = Medium AND Continual $=$ Medium THEN Framework Status $=$ Little Description

IF Artifact $=$ High AND Governance $=$ High AND Strategy $=$ Medium AND Consistency $=$ Medium AND Requirement $=$ Medium AND

4 Guidelines = Medium AND Continual = Medium THEN Framework Status = Little Description

IF Artifact $=$ Low AND Governance $=$ Low AND Strategy $=$ Medium AND Consistency = 5 Medium AND Requirement = High AND Guidelines $=$ High AND Continual $=$ High THEN Framework Status $=$ High Level Description

\subsection{Defuzzifikasi}

Defuzzifikasi adalah proses pencarian nilai keluaran yang berupa nilai crisp atau nilai z berdasarkan rata-rata dari nilai terbobot [12]. Metode yang digunakan pada tahapan proses ini adalah metode
Center Average Defuzzyfier. Proses pencarian nilai z menggunakan metode Center Average Defuzzyfier dituliskan dalam persamaan berikut.

$$
Z=\frac{\sum\left(\alpha_{-} p_{i} * z_{i}\right.}{\sum \alpha_{-} p_{i}}
$$

Dimana,

$$
\begin{array}{ll}
\mathrm{z} & =\text { defuzzifikasi rata-rata terpusat } \\
\alpha_{-} \mathrm{p} & =\text { alpha predikat } \\
\mathrm{zi} & =\text { nilai crisp hasil inferensi } \\
\mathrm{i} & =\text { jumlah aturan fuzzy }
\end{array}
$$

\section{ANALISIS DAN PENGUJIAN}

Pengujian akurasi dilakukan untuk mengetahui performa dari sistem pakar dalam memberikan hasil pengukuran performa EA framework. Dalam penelitian ini data yang diuji berjumlah 6 data dari penelitian Babak Rouhani [5]. Prosedur pengujian yang akan dilakukan adalah dengan membandingkan hasil penilaian performa EA framework dari pakar dengan

\begin{tabular}{|c|c|c|c|c|c|c|c|c|c|c|c|}
\hline Framework & $\mathrm{K} 1$ & $\mathrm{~K} 2$ & $\mathrm{~K} 3$ & KA & $\mathrm{K} 5$ & $\mathrm{~K} 6$ & $\mathrm{~K} 7$ & $\begin{array}{l}\text { Penilaian } \\
\text { Fuzzy } \\
\text { Tsulkamoto }\end{array}$ & $\begin{array}{l}\text { Predikat } \\
\text { Fuzzy }\end{array}$ & $\begin{array}{l}\text { Penllaim } \\
\text { Pakar }\end{array}$ & $\begin{array}{l}\text { Preditikat } \\
\text { Pakat }\end{array}$ \\
\hline EAP & 66 & 68 & 83 & 61 & 37.5 & 62 & 65 & 71.58 & LD & 63.2 & $\mathrm{LD}$ \\
\hline TOGAF & 78.7 & 93 & 86 & 90.5 & 95 & 85 & 91 & 91.52 & $C D$ & 88.5 & $C D$ \\
\hline DODAF & 48.5 & 48 & 70 & 21.5 & 20.5 & 48.5 & 21 & 41.58 & LD & 39.6 & HL \\
\hline Gather & 60.5 & 60 & 50 & 25.5 & 31.5 & 29.5 & 22.5 & 42.66 & LD & 39.8 & HL \\
\hline FEAF & 68.5 & 38 & 85.5 & 69.5 & 39.5 & 83 & 35.5 & 69.42 & LD & 59.9 & ID \\
\hline Zachman & 38 & 78 & 36.5 & 55 & 64.5 & 62 & 60 & 65.33 & ID' & 56.3 & ID" \\
\hline
\end{tabular}
hasil penilaian menggunakan metode fuzzy Tsukamoto. Hasil pengujian akurasi dari 7 variable masukan yang telah diuji ditunjukkan pada Tabel 5. Tabel 5. Pengujian

Dimana,

$\mathrm{CD}=$ Clear Description

LD $=$ Little Description

$\mathrm{HL}=$ High Level Description

Berdasarkan informasi yang ada pada Tabel 5 telah dilakukan pengujian akurasi dengan menggunakan 6 data penilaian performa EA framework menggunakan persamaan 8. Berdasarkan perhitungan dengan menggunakan persamaan 8 menghasilkan nilai akurasi seperti berikut :

$$
\begin{gathered}
\mathrm{NA}=\frac{\left.\sum \text { (Data Akurat }\right)}{\sum(\text { Data })} \times 100 \% \\
\mathrm{NA}=\frac{2}{6} \quad \times 100 \% \\
=67 \%
\end{gathered}
$$

Akurasi sistem pakar menggunakan metode fuzzy Tsukamoto dalam mengukur performa EA framework yang telah diuji hanya memiliki tingkat akurasi $67 \%$ 


\section{KESIMPULAN}

Dari hasil penelitian ini diketahui bahwa sistem inferensi fuzzy Tsukamoto belum cukup baik digunakan untuk mengukur performa EA framework. Dengan menggunakan data kriteria artifact, governance, strategy, consistency, requirement, guidelines, dan continual diperoleh hasil pengukuran performa dengan tingkat akurasi hanya $67 \%$ pada percobaan sebanyak 6 data EA framework.

Salah satu hal yang memberikan pengaruh cukup besar dalam hal akurasi adalah pembentukan aturan fuzzy. Pada penelitian ini pembentukan aturan fuzzy masih dilakukan secara manual berdasarkan pendapat pakar. Jika aturan fuzzy ditentukan secara manual akan lebih banyak coba-coba. Bisa jadi penentuan tersebut kurang tepat. Oleh karena itu, pada penelitian selanjutnya, dapat mengimplementasikan algoritma genetika untuk melakukan optimasi pada penentuan aturan fuzzy. Optimasi pembentukan aturan fuzzy bertujuan untuk meningkatkan skurasi sistem yang lebih baik. Algoritma Genetika telah banyak diimplementasikan untuk penyelesaian permasalahan yang berkaitan dengan optimasi.

\section{DAFTAR PUSTAKA}

[1] Roni Yunis; Kridanto Surendro; Erwin, "Pengembangan Mode Arsitektur Enterprise Untuk Perguruan Tinggi," Juti, vol. 8, no. Gambar 1, pp. 9-18, 2010.

[2] Y. Roni and Theodora, "Penerapan Enterprise Architecture Framework Untuk Pemodelan Sistem Informasi," JSM STMIK Mikroskil, vol. 13, no. 2, pp. 159-168, 2012.

[3] J. A. Zachman, "A framework for information systems architecture," IBM Systems Journal, vol. VOL 26. NO, no. 3, p. 17, 1987.
[4] T. Magoulas and A. Hadzic, "Alignment in Enterprise Architecture: A Comparative Analysis of Four Architectural Approaches.," Electronic Journal of Information System Evaluation, vol. 15, no. 1, pp. 88-101, 2012.

[5] B. D. Rouhani, M. N. Mahrin, F. Nikpay, and P. Nikfard, "A Comparison Enterprise Architecture Implementation Methodologies," in 2013 International Conference on Informatics and Creative Multimedia, 2013, no. SEPTEMBER 2013, pp. 1-6.

[6] M. Davoudi Razavi and K. Sheikhvand, "An Approach towards Enterprise Architecture Analysis using AHP and Fuzzy AHP," International Journal of Machine Learning and Computing, vol. 2, no. 1, 2012.

[7] G. Osvalds, "Definition of enterprise architecture-centric models for the systems engineer," Innovate integrate and invigorate the 11th annual symposium of the international council on systems engineering, no. JULY 2001, p. 7 pp, 2001.

[8] G. Doucet, J. Gotze, P. Saha, and S. Bernard, "Coherency Management: Using Enterprise Architecture for Alignment, Agility, and Assurance," Journal of Enterprise Architecture, no. May, pp. 1-12, 2008

[9] L. Urbaczewski and S. Mrdalj, "A comparison of enterprise architecture frameworks," Issues in Information Systems, vol. 7, no. 2, pp. 18-23, 2006.

[10] T. Murti, L. A. Abdillah, and M. Sobri, "Sistem Pendukung Keputusan Kelayakan Pemberian Pinjaman Dengan Metode Fuzzy Tsukamoto," pp. 252-256, 2015.

[11] W. Kaswidjanti, A. S. Aribowo, C. B. Wicaksono, F. Inference, and F. Inference, "Implementasi Fuzzy Inference System Metode Tsukamoto Pada Pengambilan Keputusan Pemberian." pp. 137-146, 2014.

[12] H. N. Hadi, and W. F. Mahmudy, "Penilaian Prestasi Kinerja Pegawai Menggunakan Fuzzy," Jurnal Teknologi Informasi dan Ilmu Komputer, vol. 2, no. 1, pp. 41-48, 2015.

[13] N. R. Sari, W. F. Mahmudy, "Fuzzy Inference System Tsukamoto Untuk Menentukan Kelayakan Calon Pegawai," Seminar Nasional Sistem Informasi Indonesia (SESINDO) (pp. 245-252)., no. 2002, pp. 2-4, 2015. 